\title{
Granulomatous peritonitis caused by glove starch
}

\author{
M. MICHOWITZ \\ M.D. \\ M. STAVOROVSKY \\ M.D. \\ B. ILIE* \\ M.D.
} Department of Surgery ' $C$ ' and *Institute of Pathology, Ichilov Medical Center and Sackler School of Medicine,
Tel-Aviv University, Israel

\section{Summary}

Corn starch particles are used as a surgical glove lubricant. At present there is no better alternative for this lubricant. Implantation of corn starch particles into the peritoneal cavity can induce foreign body reactions, starch peritonitis and starch granulomata, and may cause adhesions and intestinal obstruction. Starch peritonitis should be treated conservatively.

KEY WORDS: starch, granulomatous peritonitis, gloves, adhesions.

\section{Introduction}

Halsted introduced rubber gloves to surgery. Water was a failure as a lubricant for donning gloves, while talcum powder used in dry sterile gloves cause severe foreign body reactions, granulomatous peritonitis and fistulae (Eiseman, Sielig and Womack, 1947). Other agents were tried experimentally as glove lubricants (Lee and Lehman, 1947; Ignatius and Hartmann, 1972; Aarons and Fitzgerald, 1974; Ellis, 1977; Sternlieb et al., 1977), with corn starch the most successful being non-irritant and absorbable. By 1950, surgical gloves were lubricated with corn starch to which $2 \%$ magnesium oxide was added to produce a fine powder.

This paper emphasises the danger of corn starch peritonitis, an avoidable iatrogenic disease, and indicates the correct treatment when it occurs.

\section{Case report}

A 52-year-old diabetic man was admitted because of severe claudication. Following investigation, transabdominal aorto-bicommon femoral artery bypass and left lumbar sympathectomy were performed. The postoperative course was uneventful and the patient was discharged 10 days after the operation.

Reprint requests: Professor M. Stavorovsky, M.D., Head, Department of Surgery 'C', Ichilov Medical Center, 6 Rehov Weizmann, 64239, Tel-Aviv, Israel.
The patient was readmitted 5 days later with a temperature of $38^{\circ} \mathrm{C}$, vague abdominal pain and tenderness in the left lower quadrant. Abdominal Xray showed moderately distended small and large intestine. Ultrasonography and computed tomographic scan suggested a left lower quadrant intraabdominal abscess. The patient was treated conservatively by intravenous fluids, nasogastric tube and cephalothin. However, his condition deteriorated slowly and clinical and X-ray signs of dynamic intestinal obstruction appeared. At exploratory laparotomy, the small bowel was distended with gas and fluid and was found to be involved in a mass of adhesions to the omentum. The adhesions were divided and the omentum partly resected. The patient improved postoperatively and was discharged 20 days after the second operation. At a 6-month follow-up, he was well.

Histological examination of the specimen showed an omentum covered by fibrin deposits, which contained numerous starch granules. These granules on haematoxylin and eosin stained sections were amorphous and spherical. Under polarized light, they revealed a diagnostic birefringent Maltese cross configuration. Within areas of vascularized fibrocollagenous tissue, granulomatous inflammation was found, which included lymphocytes, plasma cells, neutrophils and aggregates of multinucleated giant cells of foreign body type. Some multinucleated cells contained within the cytoplasm typical corn starch, with Maltese cross pattern. Other birefringent crystals were considered to be starch which had been partially degraded by enzymatic action (Fig. 1).

\section{Discussion}

Glove manufacturers have as yet failed to formulate a practical method of glove production excluding starch powder (Nash, 1973). Introduction of starch into the peritoneal cavity via any route, directly at laparotomy or indirectly per vaginum-Fallopian tubes (Paine and Smith, 1957; Saxen, Kassinen and Saxen, 1963; Saxen and Saxen, 1965), may cause a 


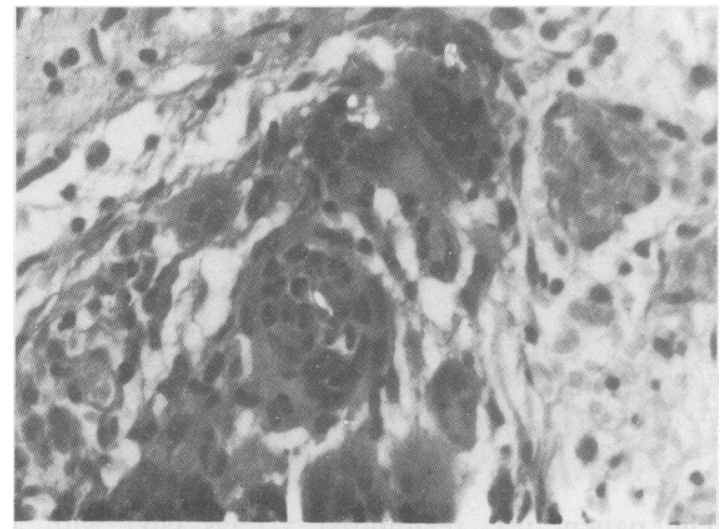

FIG. 1. Granulomatous inflammation with foreign body giant cells. Intracellular corn starch with Maltese cross pattern in the upper corner, and other birefringent crystals within other multinucleated giant cells. H.E., polarized light, $\times 256$.

foreign body reaction, and may act as a nidus for adhesion formation. This foreign body reaction may affect any operative site (Rock, 1967; Miller, 1968; Aarons and Fitzgerald, 1974). Clinical evidence for such events is available from laparotomies, postmortem examinations and experiments (Hartmann and Ignatius, 1972; Cooke and Hamilton, 1977).

Foreign body reactions may be asymptomatic and diagnosed incidentally. Other post-abdominal surgery problems, including pain, tenderness and paralytic intestinal obstruction, are caused by this reaction (Ignatius and Hartmann, 1972). Sometimes symptoms appear 2-6 weeks after the first operation. These include abdominal pain, distension, ascites, fever, anorexia, nausea and vomiting. These symptoms are suggestive of intestinal obstruction or intraabdominal abscess and are the cause of an unnecessary laparotomy. Starch dissolves and disintegrates over an interval of 2 years, but adhesions persist and may cause late intestinal obstruction. The incidence of this condition is not clear (Cooke and Hamilton, 1977).

There are experiments and some evidence that starch peritonitis is caused by a delayed hypersensitivity reaction and not by a direct toxic effect of starch (Grant et al., 1976). The evidence includes an asymptomatic period of 2-6 weeks, eosinophilia, and amelioration or dramatic improvement of symptoms by steroids (Maggs and Reinus, 1959; Webb and Regan, 1962; Holmes and Eggleston, 1972; Sternlieb et al., 1977). Although systemic steroid therapy is advocated in the treatment of established starch peritonitis, no evidence that any significant effect on the course of granuloma or adhesion was found experimentally in the rat (Cade and Ellis, 1976). In some cases, there is a granulomatous sarcoid-like inflammation (Ignatius and Hartmann, 1972; Sode berg, Lou and Randall, 1973), and positive skin teses (Bates, 1965), but in fact the reaction is related to the amount of starch present (Coder and Olander, 197 Holmes and Eggleston, 1972). In the present caş there was an uneventful recovery from the fire operation and a symptomless period of 2 weeks, un clinical symptoms appeared.

In the treatment of starch peritonitis it must be recalled that: (1) The condition is iatrogenic and possibly preventable. In spite of washing the gloves it seems impossible to avoid some degree of peritoneal contamination (Jagelman and Ellis, 1973; Sterfy lieb et al., 1977). Fraser (1980) believes that cleansing the gloves with povidone-iodine (Betadine) and the washing the gloves under running sterile wate removes the starch substantially; (2) Some cases afe apparently improved dramatically by steroids.

In the present case a pre-operative diagnosis of incomplete intestinal obstruction caused an unneces sary laparotomy.

\section{References}

Aarons, J. \& Fitzgerald, N. (1974) The persisting hazards of surgical glove powder. Surgery, Gynecology and Obstetrics, 13. 385.

BATES, B. (1965) Granulomatous peritonitis secondary to \&o $\frac{\mathbb{D}}{\square}$ starch. Annals of Internal Medicine, 62, 335.

CADE, D. \& ELLIS, D. (1976) The peritoneal reaction to starch and modification by prednisone. European Surgical Research, 8, 41 .

CODER, D.M. \& OLANDER, G.A. (1972) Granulomatous peritontiti caused by starch glove powder. Archives of Surgery, 105, 83.

COOKE, S.A.R. \& HAMILTON, D.G. (1977) The significance of starch powder contamination in the etiology of peritoneal adhesion British Journal of Surgery, 64, 410.

Eiseman, B., Sielig, M.G. \& WomaCK, N.A. (1947) Talc powd granuloma: A frequent and serious complication. Annals Surgery, 126, 820.

ELLIS, H.G. (1977) Starch peritonitis. (Letter to the Editor). Archive of Surgery, 112, 1148.

FRASER, I. (1980) Hazards of surgical glove powders. British Medica Journal, 281, 1072.

GRANT, J.B.F., DAVIES, J.D., JONES, J.V., EsPineR, H.J. \& ElTRI 굴 GHAM, W.K. (1976) Peritonitis induced by starch glove powder immunized guinea-pigs. British Journal of Surgery, 63, 669.

HaRTMANN, W.H. \& IGNaTIUS, J.A. (1972) The starch-peritonea reaction: An experimental study. Annals of Surgery, 175, 398.

Holmes, E.C. \& EGgleston, J.C. (1972) Starch granulomatous peritonitis. Surgery, 71, 85 .

Ignatius, J.A. \& HARTMANN, W.H. (1972) The glove starc? peritonitis syndrome. Annals of Surgery, 175, 388.

JAGELMAN, D.G. \& Ellis, H. (1973) Starch and intraperitonea adhesion formation. British Journal of Surgery, 60, 111.

LEE, C.M. \& LEHMAN, E.P. (1947) Experiments with non-irritatirfo glove powder. Surgery, Gynecology and Obstetrics, 84, 689.

MaGgS, R.S. \& ReINUS, F.Z. (1959) Peritonitis caused by surgicap glove starch powder treated by steroids. American Journal Surgery, 98, 111.

MILLER, W.A. (1968) Foreign body reaction to dental cone containing starch. Dental Practitioner and Dental Record, 18, 428

NASH, D.F.E. (1973) Glove powder peritonitis (Letter to the Editor British Medical Journal, 1, 485.

PAINE, C.G. \& SMITH, D. (1957) Starch granulomata. Journal of Clinical Pathology, 10, 51 . 
Rock, E.H. (1967) Surgeon's glove powder (Starch) middle ear granulomata. Archives of Otolaryngology, 86, 8.

SAXeN, L., Kaissinin, A. \& SAXen, E. (1963) Peritoneal foreign body reaction caused by condom emulsion. Lancet, i, 1295.

SAXEN, L. \& SAXEN, E. (1965) Starch granulomas as a problem in surgical pathology. Acta Pathologica et Microbiologica Scandinavica, 64, 55 .

SODERBERG, C.H. Jr., LoU, T.Y. \& RANDALl, H.T. (1973) Glove starch granulomatous peritonitis. American Journal of Surgery, 125,455 .
Sternlieb, J.J., McIlrath, D.C., VAn HeERden, J.A. \& Harison, E.G. Jr (1977) Starch peritonitis and its prevention. Archives of Surgery, 112, 458.

WEBB, D.F. \& REGAN, J.F. (1962) Starch powder granulomas in the peritoneal cavity. Archives of Surgery, 84, 282.

(Accepted 29 December 1982) 